The genus Prionailurus includes three species of medium-sized, spotted and striped cats spread across India (Mukherjee 1998). The Leopard Cat Prionailurus bengalensis (Kerr, 1792) is OPEN ACCESS widespread throughout Asia (c) (1) and most of India (Habibi 2004), whereas the Rusty-spotted Cat Prionailurus rubiginosus (I. Geoffroy Saint-Hilaire, 1831), endemic to India and Sri Lanka, occurs throughout the country. These two cats are classified as Least Concern and Vulnerable, respectively, by the IUCN Red List of Threatened Species (Ross et al. 2015; Khan \& Mukherjee 2008). Although the status and distribution of the Prionailurus cats has been well documented in other parts of India (Patel \& Jackson 2005; Patel 2006; Manakadan \& Sivakumar 2006; Vyas et al. 2007), there have been few documented studies on them in the Eastern Ghats and none in the northern Eastern Ghats. The current note records the occurrence of $P$. bengalensis and $P$. rubiginosus through camera trap images in Papikonda National Park located in Andhra Pradesh close to the borders of Odisha, Chhattisgarh and Telangana, between $18^{\circ} 29^{\prime} 31^{\prime \prime}-19^{\circ} 10^{\prime} 53^{\prime \prime} \mathrm{N}$ \& $79^{\circ} 32^{\prime} 28^{\prime \prime}-83^{\circ} 14^{\prime} 0^{\prime \prime} \mathrm{E}$. The Park covers an area of $1,012 \mathrm{~km}^{2}$, with an elevation ranging from $20 \mathrm{~m}$ to $850 \mathrm{~m}$ and straddles the Godavari River. The dominant forest type is moist deciduous, with some patches of semievergreen and dry deciduous forest (Champion \& Seth 1968).

A camera trapping study was undertaken by the authors to study the effects of landscape change on mammal diversity and distribution patterns across

\section{CAMERA TRAP RECORDS OF RUSTY-SPOTTED CAT PRIONAILURUS RUBIGINOSUS AND LEOPARD Cat Prionailurus bengalensis (Mammalia: CARNIVORA: FELIDAE) FROM PAPIKONDA NATIONAL PARK, NORTHERN EASTERN GHATS, INDIA}

\author{
Vikram Aditya ${ }^{1}$ \& Thyagarajan Ganesh ${ }^{2}$
}

${ }^{1,2}$ Ashoka Trust for Research in Ecology and the Environment (ATREE), Royal Enclave, Sriramapura, Jakkur post, Bengaluru, Karnataka 560064, India

${ }^{1}$ Manipal University, Madhav Nagar, Manipal, Karnataka 576104, India ${ }^{1}$ vikram.aditya@atree.org (corresponding author), ${ }^{2}$ tganesh@atree.org

Papikonda NP. No published studies on mammals have been undertaken in Papikonda previously.

Camera trapping was done using Trail Cam and Bushnell 8mp Digital Infra Red camera traps. Systematic sampling was carried out in different elevation zones and habitat types across the Park. Five cameras were installed in selected grids, each measuring $2 \times 2 \mathrm{~km}^{2}$ for a period of three trap nights per camera. A total of 35 grids representing various habitat types and elevation zones were surveyed between October 2014 and March 2015.

The details of the camera trap images are provided in Table 1. P. bengalensis was recorded in one camera in dense moist deciduous forest at an elevation around $270 \mathrm{~m}$, close to a rocky stream (Image 1 ). P. rubiginosus was recorded in low elevation moist deciduous forest at an altitude of $50 \mathrm{~m}$, about $2 \mathrm{~km}$ north of the Godavari River (Image 2). In addition, the Jungle Cat Felis chaus

DOI: http://dx.doi.org/10.11609/jott.2401.8.5.8818-8819 | ZooBank: urn:Isid:zoobank.org:pub:OAE07DC6-AC02-4D3D-8D2D-FA96191630DD

Editor: C. Srinivasulu, Osmania University, Hyderabad, India.

Date of publication: 26 May 2016 (online \& print)

Manuscript details: Ms \# 2401 | Received 13 November 2015 | Finally accepted 15 May 2016

Citation: Aditya, V. \& T. Ganesh (2016). Camera trap records of Rusty-spotted Cat Prionailurus rubiginosus and Leopard Cat Prionailurus bengalensis (Mammalia: Carnivora: Felidae) from Papikonda National Park, northern Eastern Ghats, India. Journal of Threatened Taxa 8(5): 8818-8819; http://dx.doi.org/10.11609/ jott.2401.8.5.8818-8819

Copyright: (c) Aditya \& Ganesh 2016. Creative Commons Attribution 4.0 International License. JoTT allows unrestricted use of this article in any medium, reproduction and distribution by providing adequate credit to the authors and the source of publication.

Funding: Conservation Leadership Programme (CLP) \# 03193914 - Future Conservationist Award.

Conflict of Interest: The authors declare no competing interests

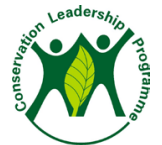

Acknowledgements: The authors would like to thank the Andhra Pradesh Forest Department for providing permission for conducting the study, and the Conservation Leadership Programme and Idea Wild for financial and equipment suppport 
Table 1. Details of recorded presence of Leopard Cat Prionailurus bengalensis and Rusty-spotted Cat, Prionailurus rubiginosus through camera trap images in Papikonda National Park

\begin{tabular}{|c|l|l|l|l|l|}
\hline & Species & Location & Date of observation & Time of observation & Location coordinates \\
\hline 1 & Prionailurus bengalensis & $\begin{array}{l}\text { Near Kondamodalu, Rampachodavaram } \\
\text { range, Papikonda NP }\end{array}$ & $25 . i .2015$ & $23: 42: 39$ to $23: 54: 42$ & $17^{\circ} 29^{\prime} 10.06^{\prime \prime} \mathrm{N} \& 81^{\circ} 33^{\prime} 37.47^{\prime \prime} \mathrm{E}$ \\
\hline 2 & Prionailurus rubiginosus & Gandi, Rekhapalli range, Papikonda NP & $02 . i .2015$ & $22: 36: 44$ & $17^{\circ} 32^{\prime} 13.41^{\prime \prime} \mathrm{N} \& 81^{\circ} 22^{\prime} 29.85^{\prime \prime} \mathrm{E}$ \\
\hline
\end{tabular}

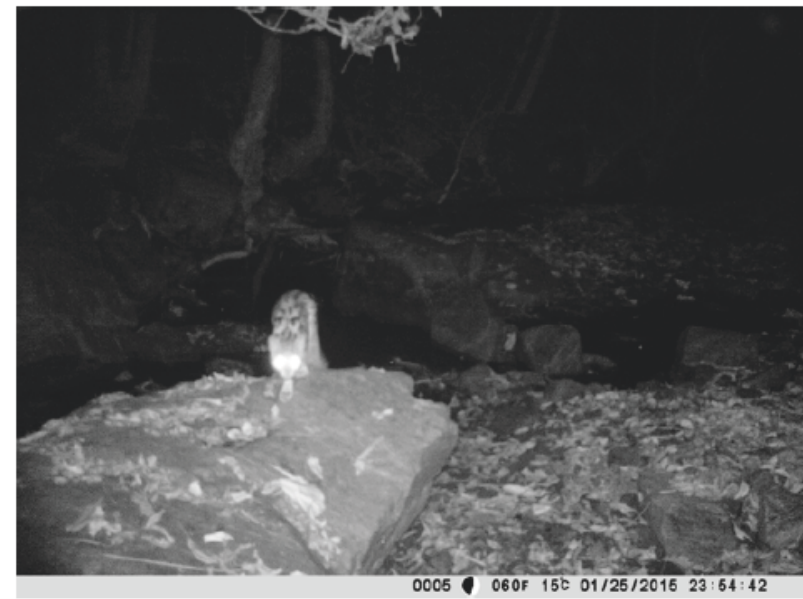

Image 1. Camera trap image of Leopard Cat Prionailurus bengalensis

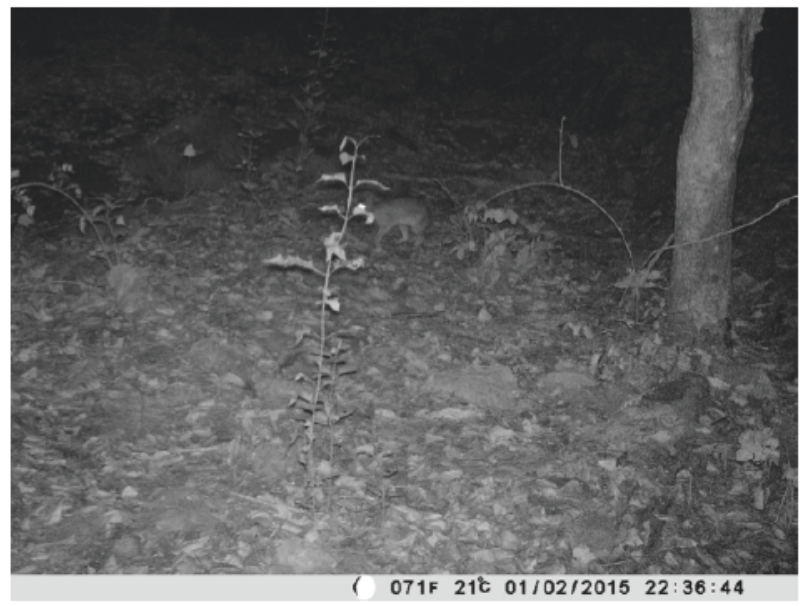

Image 2. Camera trap image of Rusty-spotted Cat Prionailurus rubiginosus

Khan, J.A. \& S. Mukherjee (2008). Prionailurus rubiginosus. The IUCN Red List of Threatened Species 2008: e.T18149A7673082. Downloaded on 18 May 2016; http://dx.doi.org/10.2305/IUCN. UK.2008.RLTS.T18149A7673082.en

Manakadan, R. \& S. Sivakumar (2006). Rusty-spotted cat on India's east coast. Cat News 45: 26.

Mukherjee, S.K. (1998). Small Cats of India. Envis Bulletin. Wildlife Institute of India.

Patel, K. (2006). Observations of Rusty-spotted Cat in eastern Gujurat. Cat News 45: 27-28.

Patel, K. \& P. Jackson (2005). Rusty-spotted cat in India: new distribution data. Cat News 42: 27.

Ross, J., J. Brodie, S. Cheyne, A. Hearn, M. Izawa, B. Loken, A. Lynam, J. McCarthy, S. Mukherjee, C. Phan, A. Rasphone \& A. Wilting (2015). Prionailurus bengalensis. The IUCN Red List of Threatened Species 2015: e.T18146A50661611. Downloaded on 18 May 2016; http:// dx.doi.org/10.2305/IUCN.UK.2015-4.RLTS.T18146A50661611.en

Sunquist, M. \& F. Sunquist (2002). Wild Cats of the World. University of Chicago Press.

Vyas, V.R., J.J. Lakhmapurkar \& D. Gavali (2007). Sighting of Rustyspotted Cat from new localities in central Gujarat. Cat News 46: 18. of India. A revised survey of the forest types of India. Govt. of India, Delhi, 404pp. 